\title{
Influence of pulmonary vascular disease and fibrosis on prognosis following closed mitral valvotomy ${ }^{1}$
}

\author{
ROWAN NICKS AND V. J. MCGOVERN \\ From the Department of Cardiothoracic Surgery and the Fairfax Institute of Pathology, Royal Prince Alfred \\ Hospital, Sydney, Australia
}

\begin{abstract}
We have examined biopsies of the lingula of the upper lobe of the left lung from 85 patients undergoing mitral valvotomy and have correlated the presence of vascular changes and fibrosis of the lung tissue with pulmonary vascular resistance, the degree and type of mitral stenosis, and the duration of pulmonary symptoms. Factors which significantly affected the prognosis were high pulmonary artery pressures, high vascular resistance, and narrowing of the pulmonary arteries; but, above all, pulmonary fibrosis. The prognosis for patients with mitral incompetence was less favourable than for those without incompetence, especially if there was increased pulmonary vascular resistance and pulmonary hypertension with axis deviation in the electrocardiogram.
\end{abstract}

That pulmonary vascular and parenchymal changes occur in patients with rheumatic heart disease is well established (Parker and Weiss, 1936 ; Evans and Short, 1957 ; Donald, Bishop, Wade, and Wormald, 1957; Aber and Campbell, 1965 ; McCredie, 1966); what is not well established is their influence on prognosis after mitral valvotomy.

Larrabee, Parker, and Edwards (1949) considered that simple decompression of the engorged vessels by mitral valvotomy should be followed by early regression of such pulmonary vascular changes that had not become irreversible. This was supported by earlier correlations of lung biopsies with the clinical behaviour of patients after closed mitral valvotomy, which seemed to indicate that pulmonary vascular disease had little influence on prognosis (Enticknap, 1953 ; Denst, Edwards, Neubuerger, and Blount, 1954 ; Clowes, Hackel, Mueller, and Gillespie, 1953 ; Goodale, Sanchez, Friedlich, Scannell, and Myers, 1955); failure to achieve permanent success was ascribed largely to cardiac and not to pulmonary factors (Turner and Fraser, 1956 ; Wood! 1954 ; Learoyd, Blacket, Sinclair-Smith, Mills, Halliday, and Maddox, 1960).

In order to find out, if possible, which factors were responsible for subsequent failure of the operation, and especially whether or not vascular and interstitial disease were important in this regard, the biopsy changes, and other factors

'Delivered to the General Scientific Meeting, Royal Australasian College of Surgeons, Melbourne, June 1966 which might be relevant, were correlated with subsequent death rates and with survival rates according to the presence or absence of these changes.

We have studied the state of the pulmonary vessels and of the interstitial tissue of the lung in 85 unselected pulmonary biopsies excised at closed mitral valvotomy operations which were performed for the treatment of clinically diagnosed tight mitral stenosis in the period 1953-57, after which time the practice was largely discontinued; furthermore, the operation was changed to a mechanical transventricular valvotomy.

\section{MATERIAL AND METHODS}

Lung biopsies were taken from the inflated lingular segment and all sections were examined by a single observer (V. J. McG.).

Vascular changes were graded according to the degree of narrowing of the lumen, using a modification of the system used by Larrabee et al. (1949). We have also accepted the criteria of Heath and Whitaker (1955), who regard vessels up to 1,000 microns in diameter as the ones most concerned in the regulation of peripheral resistance to blood flow in the lung. In arteries of this order, the ratio of medial thickness to external diameter should not be more than 1:20. Arterioles are vessels with a diameter less than 100 microns. In their normal unhypertrophied state there is no obvious muscle in the wall (Table I).

The grades of pulmonary vascular disease were correlated with pulmonary fibrosis, with the types of valvular disease found at operation, with the degree 
T A B L E I

PULMONARY VASCULAR CHANGES

\begin{tabular}{|c|c|c|}
\hline Grade & Arteries & Arterioles \\
\hline $\mathbf{I}$ & $\begin{array}{l}\text { Medial thickness more } \\
\text { than } 5 \% \text { of external dia- } \\
\text { meter }\end{array}$ & No visible muscle in wall \\
\hline II & $\begin{array}{l}\text { Medial hypertrophy + inti- } \\
\text { mal fibrosis }\end{array}$ & $\begin{array}{l}\text { Visible muscle in wall; lumen } \\
\text { diameter reduced to less } \\
\text { than double the thickness } \\
\text { of the wall }\end{array}$ \\
\hline III & $\begin{array}{l}\text { Lumen diameter reduced to } \\
\text { less than thickness of } \\
\text { arterial wall }\end{array}$ & $\begin{array}{l}\text { Lumen diameter less than } \\
\text { single thickness of wall }\end{array}$ \\
\hline IV & Necrotizing arteritis & Necrotizing arteriolitis \\
\hline
\end{tabular}

of mitral stenosis, and with the severity of dyspnoea. The numbers were too small to make any correlation with objective signs of heart failure.

We then examined survival rates in the group of 85 patients subjected to lung biopsy according to (a) the pulmonary vascular disease present, $(b)$ the degree of elevation of the pulmonary arterial pressure (moderate and severe), $(c)$ the degree of elevation of the pulmonary vascular resistance (below 250 dynes sec. $\mathrm{cm} \cdot{ }^{-5}$ and above this figure), (d) the presence or absence of pulmonary fibrosis, $(e)$ the presence or absence of mitral incompetence, and $(f)$ any association with aortic valve incompetence.

In an endeavour to clarify the problem whether or not the deaths were related to disease in the lungs, or whether these could be accounted for by an unsatisfactory mitral valvotomy operation, we examined the death rates of patients with and without evidence of obstructive lung disease (electrocardiographic changes, severe elevation of the pulmonary artery pressure, elevation of pulmonary vascular resistance above 250 dynes sec. $\mathrm{cm} .{ }^{-5}$ ) and those with and without mitral restenosis and incompetence.

Cardiac catheter data were available in 44 patients.

Pulmonary artery pressures of $40 \mathrm{~mm}$. $\mathrm{Hg}$ (mean) and above were regarded as severe, whereas below this figure or with a clinical diagnosis of elevation of the pulmonary arterial pressure they were regarded as mild to moderate.

PULMONARY VASCUlAR RESISTANCE This was calculated from the formula

M.P.A. pressure (mm. $\mathbf{H g}$ ) - M.S.A. pressure (mm. $\mathbf{H g}$ ) $\times 80.08$ dynes sec. $\mathrm{cm}^{-5}$

DEGREES OF MITRAL STENOSIS All operation patients were treated on the basis of a clinical diagnosis of tight mitral stenosis. 'Tight' refers to a valve orifice, recorded at operation, of about $1 \mathrm{sq}$. cm. or less, and 'moderate' to one larger than this. It is admitted that this measurement is subject to observer error.

Valve textures were classified as membranous, fibrotic, or calcified.

Operation death signified death in hospital during operation or during the post-operative period.
Survival rates over the period of follow-up, and $a \stackrel{\text { क्? }}{+}$ comparison of the death rates according to the presence or absence of the factors investigated, were흘 used as the 'yard-stick' for gauging any influence of $\frac{\bar{c}}{\bar{\sigma}}$ these on the prognosis of mitral valve disease follow- $\mathbb{\complement}$ ing closed mitral valvotomy.

\section{PATHOLOGY}

Pulmonary arteritis Necrotizing angiitis was not $\vec{\omega}$ found in any biopsy of the lingula. We have observed this type of reaction only in the lower lobe of necropsy material from subjects with severe mitralin stenosis (14 of 141 subjects). In this condition a patchy ${ }_{i v}^{\omega}$ necrosis affected the walls of arteries and arterioles:(particularly in the muscle of the arterial media) and a fibrosing pneumonitis surrounded the affected 0 vessels. Fibrous tissue proliferation occurred in the intima of vessels with necrotic media, narrowing the $\overrightarrow{-}$ lumen to the equivalent of grade 3 arteriopathy.

In every case in which necrotizing vascular inflam- $\stackrel{\bar{O}}{\mathcal{O}}$ mation was present in the lower lobes, the small arteries and arterioles in the upper lobes were either $\vec{\varphi}$ normal or only slightly hypertrophied. We conclude $\infty$ from this that necrotizing pulmonary arteritis occurs as a result of severe pulmonary hypertension in patients without sufficient muscular hypertrophy in the pulmonary vessels to protect them from overstretching.

Fibrosis of the lungs Usually of a patchy distribu- $\overrightarrow{\vec{B}}$ tion, this was observed in the necropsy material to $\frac{0}{3}$ be more severe in the periphery of the lobes than in $\frac{\vec{J}}{\overrightarrow{2}}$ the central parts, and more advanced in the lung bases than in the upper lobes. We found that fibrosis in the lingula was indicative of widespread disease and, in some degree, of its severity also.

\section{RESULTS OF CLINICOPATHOLOGICAL STUDY}

FACTORS ASSOCIATED WITH PULMONARY VASCULAR $\overparen{\delta}$ DISEASE Pulmonary fibrosis occurred with in-

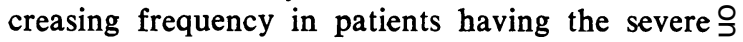
grades of pulmonary vascular disease (Table II).

\section{T A B L E I I}

\begin{tabular}{|c|c|c|c|c|c|}
\hline \multirow{2}{*}{\multicolumn{2}{|c|}{ Lung Fibrosis }} & \multicolumn{3}{|c|}{$\begin{array}{l}\text { Grade of Pulmonary } \\
\text { Vascular Disease }\end{array}$} & \multirow[b]{2}{*}{$\begin{array}{l}\text { Total } \\
\text { No. }\end{array}$} \\
\hline & & $\begin{array}{c}\text { Normal } \\
+ \\
\text { I }\end{array}$ & II & III & \\
\hline $\begin{array}{l}\text { Absent } \\
\text { Present }\end{array}$ & $\because$. & $\begin{array}{r}36 \\
2\end{array}$ & $\begin{array}{r}22 \\
7\end{array}$ & $\begin{array}{r}12 \\
6\end{array}$ & $\begin{array}{l}70 \\
15\end{array}$ \\
\hline Total & $\ldots$ & 38 & 29 & 18 & 85 \\
\hline
\end{tabular}

No association was found with pulmonary $\stackrel{\mathbb{}}{\varrho}$ vascular resistance, the degree of stenosis, the type of valve, or the severity of the dyspnoea. 
SURVIVAL RATES OF PATIENTS AFTER BIOPSY Patients with moderate or normal pulmonary arterial pressures had a much better prognosis compared with the group who had pressures in excess of $40 \mathrm{~mm}$. $\mathrm{Hg}$ mean pressure (Fig. 1).

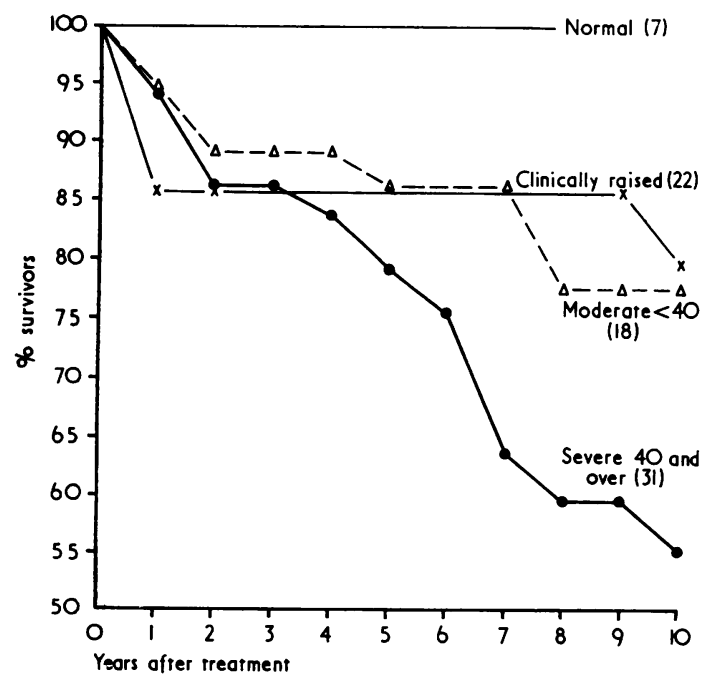

FIG. 1. Survival rate according to mean pulmonary artery pressure.

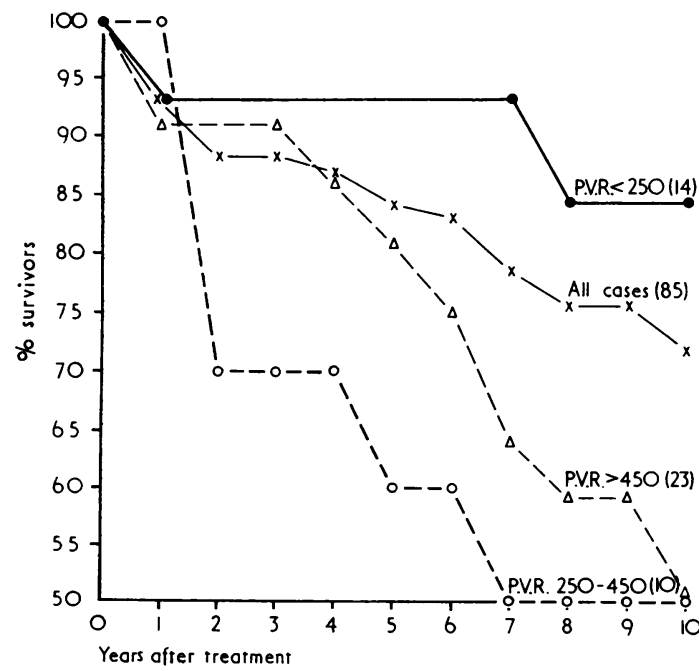

FIG. 2. Survival rate according to pulmonary vascular resistance.

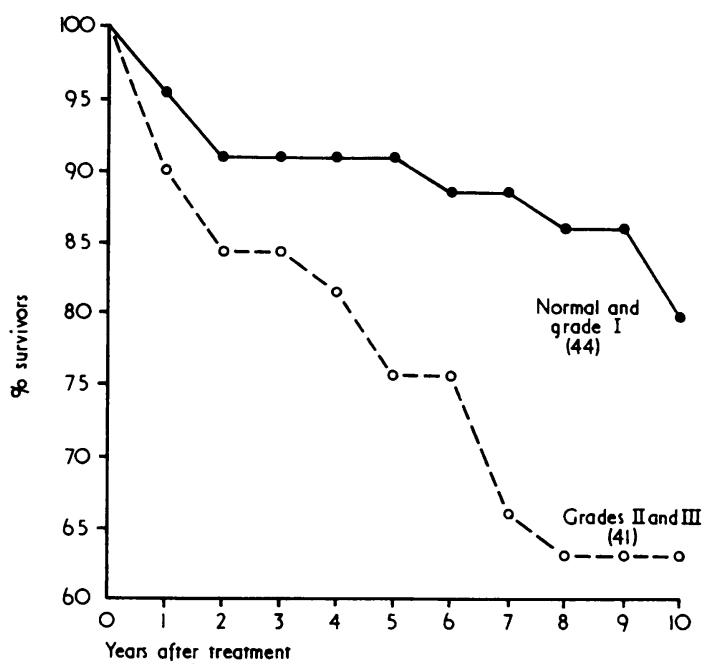

FIG. 3. Survival rate according to pulmonary vascular disease.

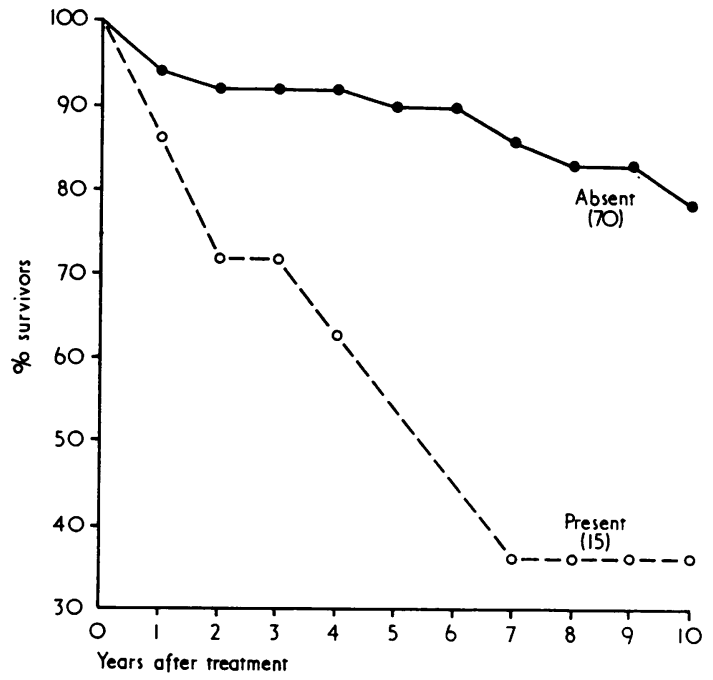

FIG. 4. Survival rate according to fibrosis.

Patients with a pulmonary vascular resistance in excess of 250 dynes-sec.-cm. ${ }^{-5}$ had a poor prognosis in comparison with the group below this figure (Fig. 2).

Patients with moderate to severe arterial disease had a higher mortality, especially in the first two years following valvotomy, compared with those with normal vessels or having only minor changes (Fig. 3).

The death rate among patients with pulmonary fibrosis was considerably higher than among those without it (Fig. 4). 
The presence of atrial fibrillation made little difference to survival (Fig. 5).

Patients with mitral incompetence (pre- and post-operative) had a poorer prognosis in comparison with the group in which this was not present (Fig. 6).

The presence or absence of associated aortic lesions had little effect on the long-term survival in this series.

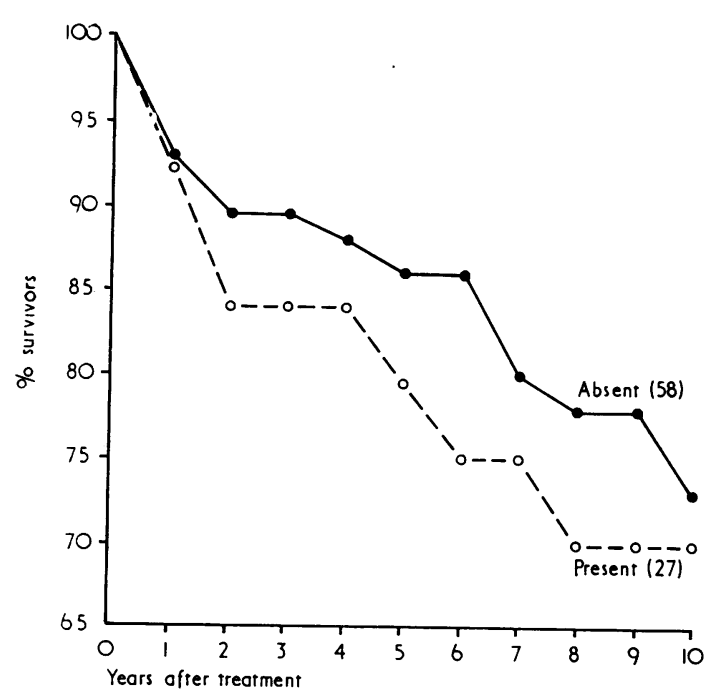

FIG. 5. Survival rate according to pre-operative atrial fibrillation.

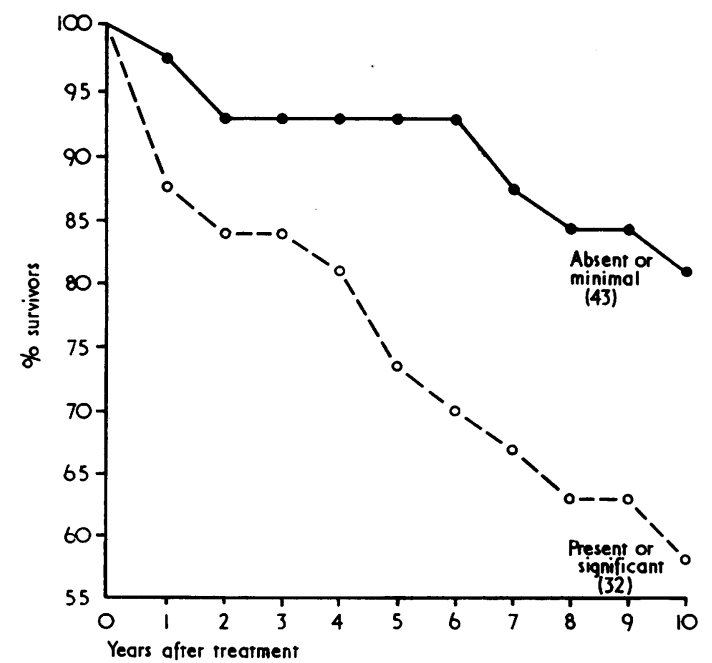

FIG. 6. Survival rate according to mitral incompetence.

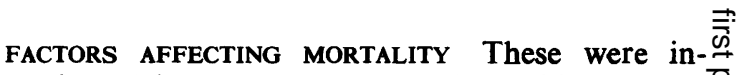
vestigated in an endeavour to find which among? several factors-namely, pulmonary vascular $\frac{\bar{\sigma}}{\bar{c}}$ obstruction, residual valvular disease (restenosis or $\frac{\vec{\sigma}}{\vec{\phi}}$ regurgitation), primary failure of the myocardium $\triangle$ from progressive disease, or combinations of these -were of significance in failure after closed $\vec{\circ}$ mitral valvotomy operations (Table III).

T A B L E I I I

\section{DEATH RATE AND ASSOCIATED FACTORS}

\begin{tabular}{|c|c|c|c|c|c|c|c|}
\hline $\begin{array}{c}\text { E.C.G. } \\
\text { Axis } \\
\text { Devia- } \\
\text { tion }\end{array}$ & $\begin{array}{c}\text { P.A.P. } \\
40 \\
\text { mm. } \\
\mathbf{H g}\end{array}$ & $\begin{array}{c}\text { P.V.R. } \\
250 \\
\text { dynes } \\
\text { sec. } \\
\mathrm{cm} .^{-5}\end{array}$ & M.I. & Alive & Dead & Total & Dead \\
\hline- & - & - & - & 6 & 1 & 7 & 12 \\
\hline- & + & - & - & 15 & - & 15 & 0 \\
\hline 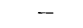 & + & - & + & 1 & - & 1 & 0 \\
\hline - & + & + & - & 1 & - & 1 & 0 \\
\hline+ & - & - & - & 8 & - & 8 & 0 \\
\hline+ & + & - & $\bar{I}$ & 15 & 6 & 21 & $\begin{array}{l}29 \\
71\end{array}$ \\
\hline+ & + & $\bar{t}$ & \pm & 2 & 5 & 17 & 71 \\
\hline & + & + & + & 1 & 1 & 2 & 50 \\
\hline & & & & 59 & 20 & 79 & \\
\hline
\end{tabular}
Note: + indicates presence of the factors and - absence. Six
patients who died of diseases unrelated to mitral stenosis were eliminated.

No significant differences in mortality could be $\overrightarrow{\overrightarrow{0}}$ discerned between patients having combinations of symptoms which might have indicated myocardial insufficiency primarily and those without these symptoms.

\section{DISCUSSION}

We regard vascular and interstitial changes in the lingular biopsy as indicative of widespread patho-logical changes throughout the lungs (Doyle, Goodwin, Harrison, and Steiner, 1967 ; Harrison, 5 1958 ; Gough, 1960 ; Aber, Campbell, and Meecham, 1963).

We have found in general an increased death rate in patients with severe vascular and parenchymal changes and elevation of the pulmonary vascular resistance which is similar to the experi- $\omega$ ence of Aber and Campbell (1965).

A high proportion of patients with pulmonaryo fibrosis had severe pulmonary vascular changes. This group had a poor survival rate, possibly ${ }^{+}$ corresponding to patients with a diminished pul $\frac{7}{0}$ monary vascular capillary bed who were found by Aber and Campbell (1965) and McCredie (1966) $\frac{\rho}{\mathrm{Q}}$ to fare badly following operation.

Patients with pulmonary hypertension and withe an elevation of the pulmonary vascular resistance 
who responded well to operation, did not have pulmonary fibrosis and their vascular changes were of mild degree. This may account for the group of patients with high pulmonary vascular resistance and normal gas diffusion who do well after operation (Aber and Campbell, 1965; McCredie, 1966). Our findings support the view that gross vascular and parenchymal changes in the lungs are not necessarily present in patients with pulmonary hypertension, even when accompanied by marked elevation of the pulmonary vascular resistance. We have observed rapid relief of pulmonary hypertension after decompression of the engorged vessels and oedematous lung parenchyma following restoration of mitral valve function in patients with minimal vascular and parenchymal changes. On the other hand, severe vascular changes, pulmonary fibrosis, and impaired gas diffusion adversely affected the prognosis (Parker and Weiss, 1936 ; Larrabee et al., 1949 ; Evans and Short, 1957 ; Aber and Campbell, 1965).

In our study the presence of mitral incompetence in combination with marked elevation of the pulmonary vascular pressure and increased pulmonary vascular resistance was of serious prognostic significance.

Braunwald, Braunwald, Ross, and Morrow (1965) found that pulmonary artery pressures and pulmonary vascular resistances gradually returned to normal after mitral valve replacement in chronic rheumatic heart disease. We believe that exudates will be absorbed after a successful mitral valvotomy or valve replacement, and that hypertrophied muscle in the pulmonary vasculature will probably regress to normal; grade 3 arterial changes and pulmonary fibrosis, however, are irreversible.

All patients have been under the care of the physicians and surgeons attached to the Hallstrom Institute of Cardiology, Royal Prince Alfred Hospital, and investigations have been carried out under the supervision of the Director.
We have been greatly helped in the follow-up by Dr. David Miller, Senior Surgical Registrar, and we are deeply indebted to Dr. Godfrey Scott, Senior Lecturer in the School of Public Health and Tropical Medicine, University of Sydney, for supervision of the statistical analysis. Dr. R. McCredie's helpful criticism is much appreciated.

\section{REFERENCES}

Aber, C. P., and Campbell, J. A. (1965). Significance of changes in the pulmonary diffusing capacity in mitral stenosis. Thorax, 20,135 .

and Meecham, J. (1963). Arterial patterns in mitral stenosis. Brit. Heart J., 25, 109.

Braunwald, E., Braunwald, N. S., Ross, J., Jr., and Morrow, A. G. (1965). Effects of mitral-valve replacement on the pulmonary vascular dynamics of patients with pulmonary hypertension. New Engl. J. Med., 273, 509.

Clowes, G. H. A., Jr., Hackel, D. B., Mueller, R. P., and Gillespie, D. G. (1953). Relationship of pulmonary functional and pathological changes in mitral stenosis. Arch. Surg., 67, 244.

Denst, J., Edwards, A., Neubuerger, K. T., and Blount, S. G., Jr. (1954). Biopsies of the lung and atrial appendages in mitral stenosis; correlation of data from cardiac catheterization with pulmonary vascular lesions. Amer. Heart J., 48, 506.

Donald, K. W., Bishop, J. M., Wade, O. L., and Wormald, P. N. (1957). Cardiorespiratory function two years after mitral valvotomy. Clin. Sci., 16, 325.

Doyle, A. E., Goodwin, J. F., Harrison, C. V., and Steiner, R. E. (1957). Pulmonary vascular patterns in pulmonary hypertension. Brit. Heart J., 19, 353.

Enticknap, J. B. (1953). Lung biopsy in mitral stenosis. J. clin. Path., 6, 84.

Evans, W., and Short, D. S. (1957). Pulmonary hypertension in mitral stenosis. Brit. Heart J., 19, 457.

Goodale, F., Sanchez, G., Friedlich, A. L., Scannell, J. G., and Myers, G. S. (1955). Correlation of pulmonary arteriolar resistance with pulmonary vascular changes in patients with mitral stenosis before and after valvuolotomy. New Engl. J. Med., 252, 979.

Gough, J. (1960). In Recent Advances in Pathology, ed. C. V. Harrison, 7th ed., p. 60 . Churchill, London.

Harrison, C. V. (1958). The pathology of the pulmonary vessels in pulmonary hypertension. Brit. J. Radiol., 31, 217.

Heath, D., and Whitaker, W. (1955). The pulmonary vessels in mitral stenosis. J. Path. Bact., 70, 291.

Larrabee, W. F., Parker, R. L., and Edwards, J. E. (1949). Pathology of intrapulmonary arteries and arterioles in mitral stenosis. Proc. Mayo Clin., 24, 316.

Learoyd, B. M., Blacket, R. B., Sinclair-Smith, B. C., Mills, F. H., Halliday, J. H., and Maddox, J. K. (1960). Dividends from mitral valvotomy: a two to seven years' follow-up. Aust. Ann. Med., 9, 224.

McCredie, R. M. (1966). The pulmonary capillary bed in various forms of pulmonary hypertension. Circulation, 33, 854.

Parker, F., and Weiss, S. (1936). The nature and significance of the structural changes in the lungs in mitral stenosis. Amer.J. Path., $12,573$.

Turner, R. W. D., and Fraser, H. R. L. (1956). Mitral valvotomy; a progress report. Lancet, 2, 525; $2,587$.

Wood, P. (1954). An appreciation of mitral stenosis. Part 2. Investigations and results. Brit. med. J., 1, 1113. 